\title{
Smart Agents in Industrial Cyber-Physical Systems
}

Paulo Leitao, Stamatis Karnouskos, Luis Ribeiro, Jay Lee, Thomas Strasser and Armando W.
Colombo

\section{Linköping University Post Print}

\section{Tweet}

N.B.: When citing this work, cite the original article.

Paulo Leitao, Stamatis Karnouskos, Luis Ribeiro, Jay Lee, Thomas Strasser and Armando W. Colombo, Smart Agents in Industrial Cyber-Physical Systems, 2016, Proceedings of the IEEE, (104), 5, 1086-1101.

http://dx.doi.org/10.1109/JPROC.2016.2521931

(C2016 IEEE. Personal use of this material is permitted. However, permission to reprint/republish this material for advertising or promotional purposes or for creating new collective works for resale or redistribution to servers or lists, or to reuse any copyrighted component of this work in other works must be obtained from the IEEE.

\section{http://ieeexplore.ieee.org/}

Postprint available at: Linköping University Electronic Press

http://urn.kb.se/resolve?urn=urn:nbn:se:liu:diva-128744 


\title{
Smart Agents in Industrial Cyber-Physical Systems
}

\author{
[removed for blind review]
}

\begin{abstract}
Future industrial systems can be realized using the Cyber-Physical Systems (CPS) that advocate the co-existence of cyber and physical counterparts in a network structure to perform the system's functions in a collaborative manner. MultiAgent systems share common ground with CPS and can empower them with a multitude of capabilities in their efforts to achieve complexity management, decentralization, intelligence, modularity, flexibility, robustness, adaptation, and responsiveness. This work surveys and analyzes the current state of the industrial application of agent technology in CPS, and provides a vision on the way agents can effectively enable emerging CPS challenges.
\end{abstract}

\section{INTRODUCTION}

Production activities face a growing set of sustainability challenges that will soon bring current industrial automation practices to their limit. At the core of these challenges [1] lie the ambitious goals of satisfying a continuously changing market with a growing demand for customized and complex products and the need to support their production in a competitive but also sustainable way. Cyber-Physical Systems (CPS) are perceived to be a core ingredient in the so called $4^{\text {th }}$ industrial revolution [2], and several efforts are pursuing its goals e.g., Industrie 4.0 [3] and Industrial Internet [4].

A cyber-physical entity is one that integrates its hardware function with a cyber-representation acting as an virtual representation for the physical part. CPS combines two worlds: (i) embedded systems, exhibiting real-time and strictly deterministic behavior, and (ii) cloud systems, highly probabilistic and optimized behavior without firm time constraints [2]. From an industrial point of view this concept opens wide the door for the development of smart products that are uniquely identifiable, localizable and able to take autonomous actions as a function of their internal state and their perception of the environment where they are immersed. It also enables the creation of sophisticated functions in complex systems like production systems or power grids. In production systems the CPS perspective partly breaks with the traditional automation pyramid [5], introducing a more decentralized way of functioning into the traditional hierarchical structure [6]. In fact, such systems would be extremely decoupled and would collectively have the ability to self-organize in order to overcome unexpected disturbances. They also support dynamic system resizing and reconfiguration to meet distinct business opportunities.

Complementing intelligent CPS with the Internet of Services (IoS), new interaction patterns and business models can be realized which may lead also to smarter products and sophisticated System-of-Systems (SoS). This disruptive vision is supported by the convergence of several developments in Artificial Intelligence (AI), Information and Communication Technologies (ICT), and the constant increase and pervasive availability of computing, communication, and storage. It must be noted that the novelty of CPS is not in establishing a new technology per se, but instead in combining existing technologies, such as Multi-Agent Systems (MAS), Serviceoriented Architectures (SOA), Internet of Things (IoT), cloud computing, augmented reality, big data, Machine-to-Machine (M2M), etc. most of which are identified as emergent technologies [7] today.

There are however important challenges, such as safety, security, and interoperability, which must be effectively tackled before this vision can become a reality especially in an industrial context. Some of these topics have been partially covered by the industrial MAS community and there are seeds of knowledge and isolated developments that could support an industrial CPS. Industrial MAS [8] are seen as playing a key role in the development of CPS, allowing to design control systems in a decentralized manner based on the distribution of control functions by autonomous and cooperative agents [9], offering important characteristics, such as modularity, flexibility, robustness, reconfigurability, and responsiveness.

However, these knowledge clusters are not consistently aggregated, nor may be adequate to fully cover CPS needs. In particular, there is not a clear connecting path between the high level design principles (e.g., holonic, bionic, fractal or reconfigurable) that set high abstraction guidelines for building what could be industrial CPS and their implementation with the hardware in-the-loop. This means that there is a subsequent and poor articulation with any precedent reference architectures, their system specific instantiation and the design of agents that may be used as a vehicle for the implementation. In the same line of thought, up to day there is no tangible way to measure the properties or quantify the specific behaviors of these emerging systems. Nevertheless, the feasibility of some key ingredients which overall render this a very active and relevant research area have been demonstrated, and may form the basis towards tackling the CPS challenges.

In this context, a fundamental part of the upcoming challenges is to connect the dots between the existing knowledge isolated parts in order to bring it one step closer to the vision. The objective of this work is to discuss the use of MAS in CPS, for implementing the next generation of industrial systems in light of key requirements such as modularity, flexibility, robustness, scalability, re-configurability, and self-adaptation. For this purpose, the paper surveys existing applications of industrial agents in CPS context and discusses the current efforts and challenges for their wider applicability.

The paper is organized as follows: section II overviews the initiatives and programs promoting the digitalization of future industrial systems and derives their requirements, and section III reviews existing agent-based applications for industrial systems. section IV introduces the design principles for these systems and section V lists important standards for their 
realization. Key challenges of using agent-oriented approaches in CPS are discussed in section VI, and section VII rounds up the paper with the conclusions.

\section{FUtURE IndUSTRIAL S YSTEMS}

Future industrial systems are being re-shaped and redesigned to address the continuous globalization and digitalization of economy, and the growing demand for increasingly complex and customized products.

\section{A. Initiatives, Programs, and Roadmaps}

The $4^{\text {th }}$ industrial revolution that is unfolding, is not based on a single technology but rather on the concept of aggregating existing system-related technologies around the cyber-physical formulation of systems. This requires a joint, convergent, and multidisciplinary research effort that is currently motivating different research initiatives and agendas. For example, aiming the development of the next generation of industrial systems, at European level the main research activities have been developed under the umbrella of "Horizon 2020 - The European Framework Programme for Research and Innovation". In particular, CPS is a key pillar in the Factories of the Future public private partnership providing a financial envelope of 1.15 billion $€$, with the general objective of developing and integrating the main enabling technologies supporting novel and adaptable machines and systems.

The European member states have themselves supported several national initiatives; for instance Germany has one of the most prominent research programs called "Industrie 4.0" [3], grounded on the vision whereby intelligent objects collect, store and process all their own relevant information throughout their life-cycle, and systems composed by these objects benefit from all the information and knowledge that is actively generated. A similar direction can also be found for example in Sweden, with the "Made in Sweden 2030" research agenda, and more recently in Spain, with strategies and initiatives following the Industrie 4.0 philosophy that support the digital businesses transformation, especially for small and medium enterprises. CPS and "Industrie 4.0" are also very important research topics in Austria where in 2015 a corresponding association with representatives from industry and research has been founded to foster innovation in this domain. The Austrian government has reserved about 250 million $€$ for research and technology development until 2017 for this area.

In the United States, CPS was identified by the President's Council of Advisors on Science and Technology report of December 2010 as national priority for the federal R\&D due to its potential scientific and technological impact to reach security and competitiveness in a number of United States' critical sectors [10]. For this purpose, the CPS program under the umbrella of the Directorate for Computer \& Information Science \& Engineering (CISE) from the National Science Foundation (NSF) is the US government's response to funding $\mathrm{R} \& \mathrm{D}$ projects in CPS. In this line, the Industrial Internet consortium [4] was announced in 2014 as a non for profit open organization created by AT\&T, Cisco Systems, General
Electric, IBM, and Intel. The consortium defines Industrial Internet as "the integration of complex physical machinery and devices with networked sensors and software, used to predict, control and plan for better business and societal outcomes" and aims to "catalyze and coordinate the priorities and enabling technologies of industry, academia and the government around the Industrial Internet”. Further north, in Canada, there is no governmental program exclusively dedicated to funding R\&D projects in CPS. Nevertheless, within the multiple programs offered by the Natural Sciences and Engineering Research Council of Canada (NSERC), several initiatives in the area of CPS are being supported. The same panorama can be found on Japan, sponsored by the Japan Science and Technology Agency (JST), an independent administrative institution for research and development framed by the Ministry of Education, Culture, Sports, Science and Technology (MEXT).

Recently, China announced its own research initiative "Made in China 2025" to support the development of more intelligent and greener manufacturing with a special focus in quality, adaptation and integration with the Internet. The China's support to R\&D projects in CPS is managed by the National Natural Science Foundation of China (NSFC), also materialized in grants awarded to researchers working in the CPS field. Finally, in Korea, private institutions and research groups related to CPS are supported by the Ministry of Science, ICT and Future Planning (MSIP).

\section{B. Requirements}

Key requirements need to be fulfilled before the vision of an integrated and convergent Industrial Internet and all its benefits can be attained. In particular, it is important to consider that, even in highly development countries there are asymmetries on the degree of digitalization of local industries and even within the same company certain areas have been prioritized with respect to computerization. As a result an "Industrie 4.0 shopfloor" as envisioned is challenging, but more importantly due to the rapid technology pace, the main paradigms that are still used in automation and control have not been able to keep up with the progress in relevant domains, e.g., computer science, artificial intelligence and engineering.

In order to overcome these challenges, companies need to understand and embrace the forthcoming technologies and principles, the networked and distributed philosophy promoted and advocated by the $4^{\text {th }}$ industrial revolution and initiate a process of change towards the development of a more cyberphysical shop floor. Current productive systems and technologies do not adequately support this view yet and until recently, for example, object orientation was completely absent from industrial programming languages. At the same time the scale of system integration required is unprecedented in industry and requires a collaborative standardization effort, that although common in other sectors, e.g., in telecommunication, has not been attained in the industrial sector.

The technical challenges are complemented by a lack of widely-acceptable models on how to design and manage and cyber-physical industrial systems. There is the need for integrated design methodologies and models that identify the 
relevant data to be collected and turned into knowledge that can, subsequently, be communicated to the different systems, supporting a cycle of continuous improvement. Knowledge generation, from the massive amount of data generated, will, to a great extent, have to be handled in an automated manner. The challenges therein far extend beyond the physical limitations related to data storage and require the design of intelligent systems that generate knowledge, which when retrofitted to the different systems, causes them to react in a "human compatible" way. Here, there are important legal and ethical implications that result from the use of advanced artificial intelligence for which there is, currently, no supporting framework.

Education needed in order to design, implement, and operate complex CPS in the emerging infrastructure is much more versatile. However, current engineering curricula are not sufficiently preparing engineers with the needed multidisciplinary background required to understand large scale, interconnected industrial CPS. Although this challenge may affect companies in a medium to long term there are more immediate education challenges towards the decision makers and employees within companies that may not be able to understand and assess the role of new industrial systems driven by CPS, and subsequently downplay its potential.

\section{Industrial APPLiCATIONS OF SMART AgENTS IN CPS CONTEXT}

MAS technology is being applied to several industrial applications in a CPS context, namely smart production (see for example [8, 11-15]), smart electric grids [16-18]), smart logistics [12]) and smart healthcare [19, 20]). This section briefly surveys and discusses existing industrial agent-based applications focusing the smart production, smart electric grids, and smart logistics domains.

\section{A. Industrial Applications in Smart Production}

Agent-based solutions for smart production have been developed and installed in industrial environments along the last two decades, as surveyed e.g., in [12,13,15], is summarized in Table I that categorizes them according to the ISA 95 levels, i.e., Automation Control (L1), Supervisory Control (L2), Manufacturing Operations Management (L4), and Business Planning and Logistics (L4).

In the mid-nineties, Rockwell Automation developed an agent-based solution to increase the utilization of steel milling process at the steel rod bar mill of the BHP Billiton in Melbourne, Australia [21]. Some years later, the same automation provider developed an agent-based real-time control system for the chilled water system on board of Us Navy ships [21]. In 2001, another early industrial application of MAS technology, developed by Schneider Automation, was installed in a factory plant of Daimler Chrysler producing engine cylinder heads [24]. The solution was in operation for five years, up to the end of the life-cycle of the targeted product, with a reported increase of $20 \%$ in productivity. One year later, the ExPlanTech agent-based production planning framework was deployed by CertiCon at LIAZ Pattern Shop
Table I

APPLICATION OF AGENTS IN SMART PRODUCTION

\begin{tabular}{|c|c|c|c|}
\hline Name & ISA95 level & Scope & Year \\
\hline BHP Billiton & L2 & Process control [21] & 1995 \\
\hline Yokogawa & L1 & Machinery control [22] & 1998 \\
\hline $\begin{array}{l}\text { MASCADA } \\
\text { (Daimler-Benz } \\
\text { pilot) }\end{array}$ & $\mathrm{L} 2$ & Manufacturing control [23] & 1995 \\
\hline Daimler Chrysler & $\mathrm{L} 2$ & Manufacturing control [24] & 2001 \\
\hline LIAZ & L3 & Production planning [25] & 2002 \\
\hline Skoda & L3 & Production planning [25] & 2002 \\
\hline $\begin{array}{l}\text { Cambridge packing } \\
\text { cell }\end{array}$ & $\mathrm{L} 2$ & Manufacturing control [26] & 2003 \\
\hline Watchdog Agent & L1 & Machinery monitoring [27] & 2003 \\
\hline FABMAS & L2 & Process control [28] & 2003 \\
\hline PABADIS & L1-L4 & Manufacturing control [29] & 2004 \\
\hline ABAS & L2 & Manufacturing simulation and control [30] & 2005 \\
\hline Saarstahl & L3 & Production process planning and monitoring [31] & 2005 \\
\hline SOCRADES & L1-L4 & $\begin{array}{l}\text { SOA-ready devices, SOA-based cross-layer integra- } \\
\text { tion (device-to-ERP) [32-34] }\end{array}$ & 2007 \\
\hline NovaFlex & L2 & Manufacturing control [35] & 2007 \\
\hline AGP & L2 & Manufacturing execution system [36] & 2008 \\
\hline ADACOR-FMS & L2 & Manufacturing control, and reconfiguration [37] & 2008 \\
\hline Axion-Holding & L3 & Manufacturing scheduling [38] & 2010 \\
\hline IMC-AESOP & L1-L4 & $\begin{array}{l}\text { SOA-ready devices, cloud-based SCADA/DCS, SOA } \\
\& \text { cloud -based services }[11,34,39]\end{array}$ & 2010 \\
\hline Kuznetsov & L3 & Manufacturing scheduling [40] & 2013 \\
\hline $\begin{array}{l}\text { GRACE (Whirlpool } \\
\text { pilot) }\end{array}$ & $\mathrm{L} 2$ & Self-adaptation [41] & 2013 \\
\hline IDEAS & L2 & Reconfiguration and plug-and-produce [42] & 2013 \\
\hline $\begin{array}{l}\text { ARUM (Airbus and } \\
\text { IHF pilots) }\end{array}$ & L3 & Production planning and scheduling [43] & 2015 \\
\hline ADACOR2 & L2 & Manufacturing control and reconfiguration [44] & 2015 \\
\hline PRIME & L2 & Manufacturing plug-and-produce [45] & 2015 \\
\hline
\end{tabular}

producing patterns and forms for automobile industry, and at SKODA Auto, Mlada Boleslav, for the production planning in the engine assembling workshop [25]. The Agentsteel system was installed in the steelwork Völklingen of Saarstahl for the on-line planning and monitoring of the steel production process [31]. A real-time MAS scheduling and optimization tool, developed by Magenta Technology, was deployed for the factory workshop of Axion-Holding, Russia [38], and later, Smart Solutions deployed a similar smart MAS for the real-time scheduling in the aircraft jet engines production at Kuznetsov, Russia [40]. A holonic Manufacturing Execution System (MES), implemented using MAS technology, was developed for the American Glass Product (AGP) [36].

MAS were also applied in prognostics and health management. The Watchdog agent toolbox, developed by Center for Intelligent Maintenance Systems (IMS), provides intelligent data processing tools for the assessment of the degradation process of machines and components. These analytical agents have been successfully implemented in several applications, such as monitoring and diagnosing air compressor equipment and machine tools components [27]. Also at machinery level, Yokogawa Electric Corporation used agent technology to develop a control system for the Shape Deposition Manufacturing (SDM) Laboratory of the Robotics Institute at Carnegie Mellon University [22].

Several large-scale R\&D initiatives were conducted along the years to research and promote the use of MAS in industrial applications. The main test-case of the EU MASCADA project 
was the development of a PROSA-based agent system for a section of the painting center in the Daimler-Benz plant in Sindelfingen, Germany [23]. Another PROSA-based agent system, entitled FABMAS, was installed for production control of a semiconductor wafer fabrication facility [28]. Also FP5 PABADIS and FP6 PABADIS'PROMISE [29, 46] targeted a distributed, agent-based manufacturing control. The test-case of the EU FP7 GRACE project deployed a MAS for integrating process and quality control in the washing machine production line of Whirlpool [41] in Naples, Italy, showing benefits in terms of production efficiency and product quality, as well as a reduction of the scrap costs. The EU FP7 IDEAS project focused on the application of key enabling technologies, and particularly MAS, to enable instant/plug and produce deployment of modular equipment without reprogramming, being demonstrated by using the Masmec System for dynamic part assembly [42].

EU FP6 SOCRADES has aimed towards service-enabled factories [47], and has utilized agent technology in various test cases, e.g., for simulating simple web-service enabled devices [32], large infrastructures of SOA-ready devices [33], up to more complex cooperative industrial systems [34]. This line of thought, was further followed within the EU FP7 IMCAESOP project, where the focus on SOA-ready devices was heavily shifted towards cloud-ready approaches [11]. A cloudbased service-oriented architecture was proposed with the aim to enhance cloud-centric interactions among disparate systems including agent-based ones [6]. Smart agents would then use these services and driven by their internal logic can take and enforce decisions, e.g., energy monitoring in a plant and usage of excess energy in electric vehicle charging or trading it in an energy market [39]. PABADIS, SOCRADES and IMCAESOP are among the rare projects that have tackled a crosslayer CPS infrastructure i.e., L1-L4 as shown in Table I.

The EU FP7 ARUM project combines MAS and SOA to develop knowledge-based applications that support mitigation strategies to respond faster to unexpected events in rampup production of complex and highly customized products, such as airplanes or shipyards [43]. The developed strategic planning and operational scheduling tools were tested in the Hamburg factory plant of Airbus producing the new A350 and in the Ferentino factory of IHF producing products for the airplane in-flight, such as coffee machines and trash compactors. The EU FP7 PRIME project proposes a MAS framework to enhance assembly systems with standardized plug and produce process and control solutions to allow rapid reconfiguration and deployment, performance monitoring, selfawareness and evolutionary system adaptation [45]. These principles were validated using two MAS-based industrial demonstrators, namely one placed at the University of Nottingham, considering "plug and produce" for reconfiguration of production systems with a minimum human intervention.

Some lab prototypes using MAS have also been realized. A large-scale industrial agent-based control testbed for assembling Gillette packages into customer-tailored gift boxes was deployed at the lab packing cell of the University of Cambridge [26]. MAS shop floor control systems were developed for the Novaflex manufacturing system at Uninova,
Portugal, using the CoBASA architecture [35], and for the flexible manufacturing system at the Polytechnic Institute of Braganca, Portugal, using the ADACOR holonic architecture [37]. An evolution of this approach, named $\mathrm{ADACOR}^{2}$, was deployed in the AIP-PRIMECA system installed in the University of Valenciennes, providing a dynamic control system reconfiguration by combining structural and behavioral selforganization [44]. At last, ABAS was deployed on a highly dynamic, reconfigurable micro-assembly station at Tampere University of Technology in Finland, aiming the 3D simulation and visualization of assembly processes [30].

\section{B. Industrial Applications in Smart Electric Grids}

ICT is being applied in smart electric grids to enhance the achievement of intelligent and collaborative control systems that cope with the increasing complexity, volume of data and non-linearity exhibited by these systems. The use of ICT, and particularly agents and SOA, in intelligent energy systems is reviewed, e.g., in $[16,17]$, and is summarized in Table II.

Table II

APPLICATION OF AGENTS IN SMART ELECTRIC GRIDS

\begin{tabular}{lll}
\hline Name & Automation functions & Year \\
\hline CRISP & Active Control, Distributed Control and Monitoring [48] & 2005 \\
\hline GridAgents & Distributed Control and Monitoring, Demand Response [49] & 2008 \\
\hline Fenix & $\begin{array}{l}\text { Demand Response, Distributed Control and Monitoring, Ac- } \\
\text { tive Control [50] }\end{array}$ & 2008 \\
\hline IDAPS & $\begin{array}{l}\text { Distributed Control and Monitoring, Demand Side Manage- } \\
\text { ment [51] }\end{array}$ & 2009 \\
\hline SmartHouse/ & $\begin{array}{l}\text { Demand Side Management, Demand Response, Distributed } \\
\text { SmartGrid }\end{array}$ & 2009 \\
\hline OPTIMATE & Distributed Control and Monitoring [54] & 2010 \\
\hline More & $\begin{array}{l}\text { Demand Side Management, Distributed Control and Monitor- } \\
\text { ing, Active Control [18, 52, 55] }\end{array}$ & 2010 \\
\hline Integral & Distributed Control and Monitoring, Active Control [56] & 2011 \\
\hline MASGrid & $\begin{array}{l}\text { Distributed Control and Monitoring, Active control, Self- } \\
\text { Optimization [57] }\end{array}$ & 2011 \\
\hline BeyWatch & $\begin{array}{l}\text { Demand Side Management, Demand Response, Distributed } \\
\text { Control and Monitoring [58] }\end{array}$ & 2011 \\
\hline EcoGrid & Demand Side Management, Self-optimization [59] & 2012 \\
\hline UNLV pilot & Demand Side Management, Peak Load Management [60] & 2012 \\
\hline GRID4EU & Demand Side Management, Peak Load Management [61] & 2013 \\
\hline NOBEL & User-bidding in Energy Marketplace [62, 63] & 2013 \\
\hline E2SG & $\begin{array}{l}\text { Distributed Control and Monitoring, Network Reconfiguration } \\
\text { [64, 65] }\end{array}$ & 2014 \\
\hline & & \\
\hline
\end{tabular}

The CRISP project developed the PowerMatcher tool aiming the supply-demand balancing by using an agent-based electronic market [48]. This tool was used in several followup projects, e.g., Integral and SmartHouse/SmartGrid projects. Integral focuses on the development of a MAS application to coordinate a cluster of devices to match its electricity supply and demand [56], and SmartHouse/SmartGrid utilized agent technology to autonomously monitor and control a power grid according to enterprise dynamically communicated needs [18, 48, 52]. In addition, for the last case, agents have been used for simulation of energy behaviors at system level e.g., smart grid cities [53]. The EU FP7 EcoGrid project also reused the PowerMatcher tool to implement a real-time energy market 
[59] for the Danish Bornholm island, which comprises around 2000 residential consumers.

The More Microgrids project used MAS to implement the intelligent control of micro grid loads to maintain the balance between the energy demand and supply through a selective shedding of non-priority loads [18, 52, 55], and the Intelligent Distributed Autonomous Power Systems (IDAPS) project aims to supply the critical loads when a failure with the utility grid connection is detected [51]. The MASGrid project [57] applies MAS technology for the self-optimization in active power distribution grids aiming to reduce line losses and to maintain the power quality impacted by a high amount of fluctuating distributed generators.

The GridAgents tool was designed to support the development of large-scale distribution network control solutions comprising big amount of distributed energy resources [49] and was tested in the Fulton Corridor Network and Madison Square Network in New York City.

The NOBEL project created a cloud-based platform offering energy services including a market where energy could be traded by agents representing their users $[62,63]$. The E2SG project was developed a decentralized and embedded agent oriented architecture for the optimization and management of intelligent buildings [64], and an asynchronous leaderless MAS-based approach that coordinates the reactive power outputs of a set of power capacitors [65]. The GRID4EU project uses MAS for surveillance and automated control of medium voltage grids [61], the OPTIMATE project uses MAS to ease the analysis and validation of market designs [54], and FENIX applies MAS to prevent electric imbalance in commercial clusters of distributed energy resources [50]. The University of Nevada, Las Vegas (UNLV) developed an intelligent agent software system to integrate residential customers aiming potential energy savings, contributing for decreasing the peak demand in the Desert Southwest [60]. The BeyWatch project presents an innovative energy-aware and user-centric solution, where intelligent agents provide intelligent energy monitoring/control and power balancing to residential customers [58].

Other examples found in literature use MAS to support the balance of supplied and demanded energy (e.g., [66, 67], the micro grid operation (e.g., [55]), and the self-healing capability of a smart grid (e.g., [68-70]).

\section{Industrial Applications in Smart Logistics}

Several applications of MAS in scheduling and logistics optimization are also reported in literature, illustrated in Table III.

Nutech Solutions developed for Air Liquide America LP a MAS solution, enhanced with ant-based strategies, to reduce the distribution costs by managing the truck routes for delivering industrial and medical gases [74]. The Southwest Airlines used a software solution, developed by BiosGroup, integrating ant-based algorithms to get planes to available gates faster at the Sky Harbor International Airport in Phoenix, US [71]. Magenta Technology has implemented a series of MAS applications for the real-time scheduling and logistics for different domains, namely taxi scheduling implemented for
Table III

APPLICATION OF AGENTS IN LOGISTICS

\begin{tabular}{lll}
\hline Name & Scope & Year \\
\hline Southwest Airlines & Ground floor operations optimization [71] & 2001 \\
\hline ABX Logistics & Real-time transport optimization [72] & 2005 \\
\hline Tankers International & Real-time scheduling [73] & 2006 \\
\hline GIST & Real-time routing and scheduling [73] & 2007 \\
\hline Air Liquide America & Logistics optimization [74] & 2008 \\
\hline $\begin{array}{l}\text { Airport ground ser- } \\
\text { vices operations }\end{array}$ & Planning and scheduling [75] & 2008 \\
\hline Addison Lee & Real-time taxi scheduling [76] & 2009 \\
\hline Avis & Rent a car optimization [77] & 2009 \\
\hline $\begin{array}{l}\text { Ciudad Real Central } \\
\text { Airport }\end{array}$ & Airport ground handling management [78] & 2012 \\
\hline Prologics & Real-time truck scheduling and routing [79] & 2012 \\
\hline RusGlobal & Real-time truck scheduling and routing [79] & 2012 \\
\hline Lego & Real-time scheduling [80] & 2013 \\
\hline MASDIMA & Monitoring \& real-time adaption in airline operations & 2014 \\
\hline Russian railways & Real-time train scheduling [82] & 2015 \\
\hline & &
\end{tabular}

the Addison Lee taxi company [76], routing and scheduling for the GIST logistics company [73], rent a car optimization for Avis, UK [77] and real-time scheduling of cargo assignment to vessels for Tankers International [73]. In a similar manner, Smart Solutions has implemented a series of MAS applications for the scheduling and logistics for different domains, namely adaptive real-time train scheduling for the Russian railways [82] and real-time truck scheduling and routing for Prologics and RusGlobal [79]. The achieved benefits are related to the reduction of the needed resources, reduction of the reaction time in response to disruptive events and increased effectiveness of resource management.

Whitestein Technologies has introduced a MAS real-time transport optimization solution for ABX Logistics, which an overall cost saving of $11,7 \%$ and an improvement in the process efficiency of around 30\% [72]. Multi-Agent Technology Group designed a real-time MAS scheduling for the LEGO Company supply chain, which during the yearlong trial period provided the following achievements: reduction of lost sales from $40 \%$ to $16 \%$, increase in service level from $66 \%$ to $86 \%$ and increase in profitability from $56 \%$ to $81 \%$ [80]. MASDIMA was prototyped in the Portuguese airline TAP company aiming to monitor and real-time solve problems after disruption during the execution of the airline operation [81]. University of Castilla-La Mancha prototyped a MAS decision support system for the airport ground handling management at the Ciudad Real Central Airport in Spain [78]. Knowledge Genesis in collaboration with Cologne University of Applied Sciences and Airbus, developed a MAS for planning airport ground service operations, such as air-catering, luggage delivery and aircraft clean-up [75].

\section{Discussion}

The analysis of the surveyed applications allows to extract some important conclusions related to the adoption of agent technology to develop industrial large-scale CPS. 
The areas of interest covered by MAS are growing, covering the span of CPS application domains. In fact, initially, industrial applications were more focused in manufacturing domain, started in 1995 and consolidated in 2001 with the Daimler Chrysler application, but lately new application fields are emerging, namely smart electric grids, logistics and smart health (illustrated by an increase in the number of industrial applications in the last years).

In terms of application scope, initially, the industrial application of MAS was more focused in planning and scheduling. Currently, an expansion to other topics like monitoring, control, self-adaptation, and simulation is noticed. Another observation is the discrepancy of the number of industrial applications found in manufacturing and continuous processes, which may be justified by the harder technical requirements found in the last one.

The review also shows that the adoption of agent technology in industrial applications demanding hard real-time constrains is still not expressive. For this purpose, other technologies that ensure real-time control can be combined, e.g., IEC 61131-3 and IEC 61499, being MAS more focused with higher levels to provide intelligence and responsiveness. In the same line, recently, MAS is being combined with other complementary technologies, notably SOA, cloud computing, data mining, augmented reality and wireless sensor networks. Currently, applications in smart electric grids frequently combine these key technologies. An emerging topic, noticed in the most recent applications, is the integration of data mining algorithms to develop distributed big data analytics.

An important issue when reviewing the industrial application of a technology or solution is to analyze the Technology Readiness Level (TRL), which reflects the technology's maturity. From the spectrum of analyzed industrial applications, the majority of applications developed for smart production is centered in TRL 6-7 (mainly those related to demonstrators of $R \& D$ projects), but some applications have reached TRL 9, namely the application deployed in Daimler Chrysler. In logistics, the level of maturity is higher, being centered mainly in TRL 7-9, probably justified by the fact that these applications are operating at scheduling and optimization level, not facing some industrial constraints, e.g., real-time control or integration with physical automation devices.

At last, it is important to refer that several commercial software companies, such as Magenta Technology, Smart Solutions, NuTech, Certicon, Almende, Multi-Agent Technology and Whitestein Technologies, as well as some automation providers companies, such as Rockwell Automation and Schneider Electric, are already offering industrial solutions based on MAS technology.

\section{DESIGN PRINCIPLES}

The requirements imposed to future industrial systems are challenging the cyber-physical conceptualization and the design of any system is fundamentally different from its, counterpart, more conventional design practices. Although it is possible to argue that all automated systems are cyber-physical in a way, since they result from the coupling of computing elements with physical elements, the vision promoted by the $4^{\text {th }}$ industrial revolution requires smaller, more intelligent and modularized cyber-physical entities that are function-oriented are required for their realization.

It is fundamental to consider a connected and integrated approach to system design that links high-level design abstractions and principles, such as holons, services, agents, emergence, self-organization and self-adaptation, with the final, other systems-in-the-loop, implementation [83]. The harmonization of these dimensions is an important challenge that can be better appreciated by considering the design along five different stages as illustrated in Figure 1, and the specific challenges associated to each one [83].

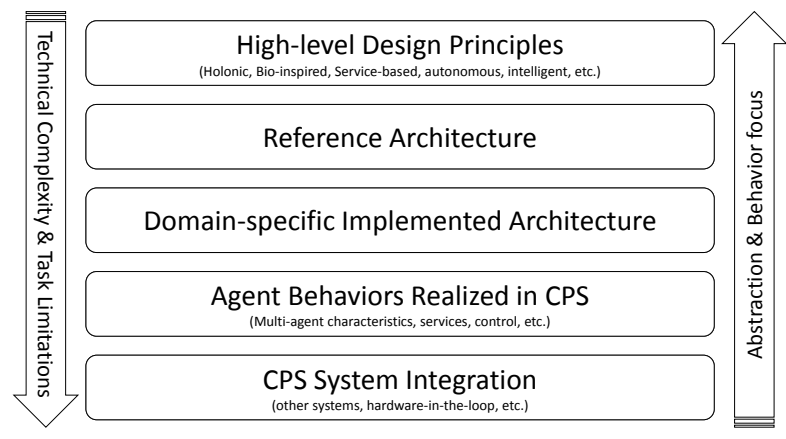

Figure 1. Design principles for agent-based CPS (adapted from [83])

High Level Design Principles: the cyber-physical formulation of a system has been traditionally inspired by biological or physical systems displaying through-life properties that are highly desirable in engineered systems. These include a persisting ability to react and adapt to quickly changing environmental conditions by dynamically adjusting their structure or operational mode and gracefully recovering from disturbances. This results in an extreme case of robustness that ensures the survival of the system. The key ingredients that grant such behaviors to natural systems relate to the number of system components, the existence of functional redundancy in association to a highly decoupled control structure and a convergent response that collectively allows the system to explore different solutions for a given disturbance. These ingredients have, for a long time now, been incorporated as high level design principles on most agent-based industrial systems but their implementation at industrial level has been rather elusive.

Reference Architectures: a considerable number of high level design properties are lost during the formulation of reference architectures. System architectures, acting as blueprints for the creation and generalization of agent based systems have to incorporate, in a technical framework, not only the high level design principles as well as the specific engineering and technical details of an industrial system. In [84] the authors distinguish between the primary, value adding, functions of an architecture and its life-cycle properties and this is a crucial point in design. The primary function of a natural system is to survive and certain natural systems will take or promote significant losses in order to attain its goal. In an engineered system, although one is interested in the life-cycle 
properties of natural systems, losses have to be avoided. In addition, and contrary to natural systems, engineered system are fairly heterogeneous. The implementation of the desired life-cycle properties requires the identification of the classes of value-adding components, their functions, interactions and structural organization. This must ensure a minimum level of harmonization that enables the design of self-organizing patterns resulting in the desired life-cycle properties. The reference architecture should be as technology and system agnostic as possible to maximize range of systems in which it can be instantiated.

Instantiated System Specific Architecture: the true value of an architecture can only be observed once it comes into operation in a concrete system. A reference architecture, if properly designed, can generate a multitude of different systems. Even if the starting point is an existing system, where the architecture has been previously instantiated, with a specific set of constrains there are often several ways in which the system can be modified. This implies that a good design must be supported by metrics that quantify how the instantiation adheres to the primary goals and to the desired life-cycle properties. Without such a set of metrics, it is indeed impossible to objectively guide decision making of how to build a system. The ability to reconfigure the system is one of the main primary goals of cyber-physical design and is one of the distinguishing factors of systems compliant to the $4^{\text {th }}$ industrial revolution. Reconfiguration is understood as multi-objective, not restricted to the physical modification of the system, and could include sustainability aspects, such as energy savings, reuse of equipment and optimal use of human resources.

MAS Behavior/Control Design: while the previous three design stages develop in an abstract framework, the ability to instantiate an architecture requires the development of a IT platform that can support the cyber-representation of the system. At this stage several technical design decisions should be considered including the choice of the supporting technologies and the development of a concepts for how to manage the interactions between the cyber and physical parts of the system. There have historically been two main trends to connect the cyber to the physical part [85]: (i) the use of embedded agents whereby each value adding component in the system has its own computing device hosting cyberrepresentation that takes full control over that equipment, and (ii) the use of agents connected to the system, but not necessarily embedded within each component, and where the agents do not exert full control over the equipment but rather influence its behavior in the medium to long terms. The emergence of cloud computing is also opening additional possibilities, such as running the agents in computationally powerful environments with a permanent connection to local controllers. In the former case, depending on the timing requirements of the system, the agent may be able to take full control remotely. When the design moves from the conceptual sphere (first 3 levels) to the implementation sphere (last 2 levels), it is fundamental to ensure that the IT platform strictly adheres to the principles formalized in the reference architecture.

Other systems-in-the-loop implementation: finally in the last stage of design one must consider the scope of action of the MAS. Most of the existing solutions have focused in control, planning/scheduling and supervision at a level that positions them on the bottom stages of the the ISA 95 model and predominantly at MES (Manufacturing Execution Systems) level. However, as mentioned before, there is a certain level of harmonization required to generate a convergent and self-organizing response at system level. This requires the creation of several interfaces including: an interface that abstracts the interaction with heterogeneous hardware, ensuring that different components can behave or be abstracted as one of the value-adding cyber-physical entities described in the architecture, an interface that abstracts human-system cooperation and interaction in a easy, safe and secure way and offers the user an intuitive interaction with the system and an interface that connects the system with other business tools. These interfaces are seen as difficult to design since they encode the assumptions that the CPS imposes or requires from the external system to operate in accordance to its conceptual design principles. Security is a major challenges and concern given the open nature of the existing supporting technologies.

\section{Standards FOR Integrating AgEnts And CPS}

Standardization is key in order to realize interoperable and scalable solutions based on the integration of smart agents in industrial CPS environments. Since industrial CPS is a new development field, there are not many standards available up to now but supporting approaches from service-oriented, agent, real-time control and communication domain already exist.

SOA-based concepts and web services are key issues for realizing agent-based solutions (see [8, 32-34, 86, 87]). In this domain the Devices Profile for Web Services (DPWS) as well as the Representational State Transfer (REST) provide important approaches [11]. DPWS, defined by the Advancement of Structured Information Standards (OASIS), deals with the ubiquitous device integration using web services embedded in distributed devices. REST can be seen as alternative integration approach emerged out of the world wide web initiative and focuses mainly on the M2M communication.

In the domain of industrial agents, the Foundation for Intelligent Physical Agents (FIPA - www.fipa.org) has established a series of specifications for the development of MAS solutions. Examples are the FIPA Abstract Architecture specifications, which deal with abstract entities that are required to build agent services and an agent environment, and the FIPA Agent Communication specifications, which deal with the definition of the Agent Communication Language (ACL) and interaction protocols. FIPA is currently the only standard for the development of MAS systems, and is usually adopted by the agent developers community mainly due to the high popularity of JADE agent platform, which is FIPA compliant.

For the realization of (real-time) control tasks used in industrial environments, the following standardized approaches are available: the widely well known IEC 61131 standard defines a software model for Programmable Logic Controllers (PLC) with a corresponding execution model for cyclic and eventdriven execution of control tasks [88]. Moreover, five different 
programming languages have been defined within IEC 61131 to satisfy the domain-specific needs in industrial control. A further standard in the control domain is introduced by IEC 61499 that defines a Function Blocks oriented reference model for distributed, reconfigurable automation and control systems [89]. Compared to IEC 61131, a pure event-driven execution approach is introduced by IEC 61499 which has especially been defined to cover the important requirements of portability, (re-)configurability and interoperability for distributed control. This standard provides basic services supporting the reconfiguration of distributed control applications from third entities like agents or higher-level, supervisory control. A domainspecific approach for process control based on IEC 61499 is introduced by IEC 61804, which also uses function blocks in a distributed environment.

A further important part of industrial agent-based CPS approaches is the communication between different devices $[8,34]$. In this area, some essential approaches have to be taken into account. The Extensible Messaging and Presence Protocol (XMPP) provides an XML-based format for the realization of a message-oriented middleware introduced by IETF as RFC 6120, RFC 6121 and RFC 6122. This open standard allows the near-real-time exchange of data between several network entities in a publish-subscribe manner. XMPP is currently adopted as transport protocol as part of the IEC 61850 interoperability and communication approach for smart grids. Related approaches are the Message Queue Telemetry Transport (MQTT) as well as the Simple Object Access Protocol (SOAP). MQTT is a light-wight M2M communication protocol over the Transmission Control Protocol (TCP) applying the publishsubscribe pattern. It is standardized by OASIS and mainly used in IoT applications. SOAP was introduced by the World Wide Web Consortium (W3C) as communication protocol for the exchange of information between web services. Similar to the aforementioned approaches, it uses XML-based syntax for the message format over other application layer protocols like Hypertext Transfer Protocol (HTTP) or Simple Mail Transfer Protocol (SMTP). Finally, IEC 62541, called OPC Unified Architecture (OPC UA) [90], is an interesting communication approach to harmonize the information exchange in industrial systems. It defines a generic data model and web-service based communication protocol suitable for industrial applications. Both OPC-UA and DPWS have been demonstrated in cloudbased CPS industrial environments [8, 34], including interaction of agents with such services [39].

In spite of available standards, standardization is a crucial factor for the industrial adoption of agent technology, and should be addressed in the near future. Actions regarding the compliance of existing industrial standards, the tuning of existing standards in the agents field according to industrial requirements and the establishment of new standards are mandatory. An example of the last point is the effort conducted by the IEEE Standards Association to establish recommended practices for the integration of agents with lowlevel automation functions. In fact, there are different ways to connect agents with real-time control tasks, as analyzed [91], and the first potential approaches have been identified as using mainly elements as defined in IEC 61131 (i.e., communication function blocks) and IEC 61499 (i.e., communication service interface function blocks). Apart from the agent interface to real-time control, also the design and deployment methods as well as metrics and benchmarking criteria are examples of important issues which need further standards in order to integrate MAS technology in CPS-based industrial environments.

\section{Vi. Key Challenges of Agents in CPS ConteXt}

Agents and CPS share common ground. As such, agents may act as enablers for CPS to realize their vision goals. Table IV indicates industrial agent characteristics that may contribute for the CPS demands and challenges [92], pointing out also potential directions that may benefit of using agents features to achieve the CPS demands.

A detailed survey on the key factors that impact the industrial adoption of agent technology [93], shows the way to better understand and act in order to improve the industrial adoption level, mainly identifying the associated challenges. Several main challenges can be identified, namely in terms of technology/solution maturity, methodologies and tools, human in the loop, smooth migration and self-* properties, besides the standardization already discussed in the previous section.

The use of proven and well maturated technology is crucial to convince industrial stakeholders, since they are very conservative and demand proven technological solutions. In fact, some existing industrial agent-based applications already achieved high TRLs, particularly in logistics domain, but more industrial applications exhibiting higher TRLs is required, and particularly TRL 9 (i.e., actual system proven in operational environment).

Based on the inherent capabilities of agents, the emergent behavior will appear naturally from the interaction among distributed and autonomous agents. In this process, the resulting patterns are more complex than the individual behaviours from which they emerge. The complexity is also due to the sensitivity of initial conditions (butterfly effect) and to the non-linear interactions involving amplification and cooperation processes. Since the emergent behavior is difficult to predict, a pertinent challenge is related to the development of mechanisms that ensure that not expected and not desired properties will not emerge in this complex and non-linear process. Another similar issue is the digitalization and implementation of self-* properties, and particularly self-organization, selfadaptation, self-optimization and self-healing, which are key issues in the Industrie 4.0 philosophy. In fact, the inspiration from nature and biology can bring tremendous benefits in developing more adaptive, responsiveness and evolvable CPS systems, since very simple mechanisms can solve very complex problems. The challenge is to properly translate these mechanisms to the target application domain, considering the particular characteristics and constraints, and not simple copy them. Additionally, the encapsulation of agents' functionalities as services also allows to hide the associated complexity from the users as black boxes. The composition and orchestration considering self-* properties are also important in the design of such agent-based systems.

An important issue regarding the development of CPS, and often neglected in the past, is the consideration of the human- 
Table IV

Relevant Industrial Agent Characteristics \& Potential Contribution to CPS Demands

\begin{tabular}{|c|c|c|c|}
\hline Emerging CPS Aspects & Relevant Agent Characteristics & Agent Applicability & Utilization Example \\
\hline $\begin{array}{l}\text { Integration, modularity, } \\
\text { servification, collaboration }\end{array}$ & $\begin{array}{l}\text { Agents rely on modularization, interaction among other } \\
\text { agents, intelligence and adaptation, which can act as enablers }\end{array}$ & Very Good & $\begin{array}{l}\text { Glue disparate systems, wrap legacy infrastructure, enable collabora- } \\
\text { tive interactions, design patterns of distributed systems }\end{array}$ \\
\hline $\begin{array}{l}\text { Human Computer Interac- } \\
\text { tion }\end{array}$ & $\begin{array}{l}\text { In Agents, significant efforts have been directed towards } \\
\text { having them acting as human delegates and running according } \\
\text { to their owner's profiles / goals }\end{array}$ & Good & $\begin{array}{l}\text { Act as user representatives in complex processes, adjust operational } \\
\text { behavior according to user preferences, provide dynamically customiz- } \\
\text { able user interfaces }\end{array}$ \\
\hline $\begin{array}{l}\text { Autonomic and self-* fea- } \\
\text { tures, emergent behavior }\end{array}$ & $\begin{array}{l}\text { Agents can provide intelligence and self-* properties e.g., } \\
\text { self-adaptation, self-optimization, self-configuration and self- } \\
\text { healing. Based on inherent capabilities of agents, the emergent } \\
\text { behavior may appear from the interaction among the individ- } \\
\text { ual agents }\end{array}$ & Very Good & $\begin{array}{l}\text { Utilize autonomic and self-* behaviors to act as enablers in CPS, } \\
\text { including high-level interactions inspired e.g., from biological systems, } \\
\text { complex systems and swarms }\end{array}$ \\
\hline $\begin{array}{l}\text { Infrastructure and service } \\
\text { migration }\end{array}$ & $\begin{array}{l}\text { MAS have been used to capture and expose common func- } \\
\text { tionalities among systems, represent behaviors of legacy sys- } \\
\text { tems etc. }\end{array}$ & Fair & $\begin{array}{l}\text { Agents can be utilized to test various migration approaches, to func- } \\
\text { tionally glue legacy and new systems via API migration, etc. }\end{array}$ \\
\hline $\begin{array}{l}\text { Simulation of CPS and } \\
\text { large-scale CPS SoS }\end{array}$ & $\begin{array}{l}\text { Agents have proven to be capable of performing sophisti- } \\
\text { cated simulations, e.g., Agent-based Modeling and Simulation } \\
(\mathrm{ABM}) \text { is well-investigated. }\end{array}$ & Very Good & $\begin{array}{l}\text { Agents can be used to simulate large numbers of CPS, interactions } \\
\text { and behaviors, as well as complex ecosystems, e.g., CPS SoS }\end{array}$ \\
\hline $\begin{array}{l}\text { Data management, transfor- } \\
\text { mation, analytics, knowl- } \\
\text { edge extraction }\end{array}$ & $\begin{array}{l}\text { Agents have been widely used for data mining, and with } \\
\text { embedded algorithms they can also support distributed data } \\
\text { analytics scenarios }\end{array}$ & Good & $\begin{array}{l}\text { Agents can be used for data mining at the point of action, data } \\
\text { filtering and aggregation, initial analysis, distributed processing, derive } \\
\text { intelligent autonomous strategies, and support approaches that combine } \\
\text { local (fast reaction) and global (optimized and robust) data analysis }\end{array}$ \\
\hline Artificial Intelligence & $\begin{array}{l}\text { Agents have been widely used in conjunction with Artificial } \\
\text { Intelligence, planning, learning, knowledge representation, } \\
\text { neural networks, control theory, etc. }\end{array}$ & Very Good & $\begin{array}{l}\text { Capabilities of Artificial Intelligence at large can be supported via } \\
\text { agents and empower CPS with these capabilities e.g., to learn, adjust } \\
\text { and reconfigure }\end{array}$ \\
\hline $\begin{array}{l}\text { Knowledge-driven risk } \\
\text { analysis and decision } \\
\text { making/management }\end{array}$ & $\begin{array}{l}\text { Agents have been used in knowledge representation in on- } \\
\text { tologies, knowledge extraction, knowledge management, etc., } \\
\text { and applied it in decision making scenarios }\end{array}$ & Good & $\begin{array}{l}\text { Agents can be utilized to manage knowledge and analyze risks as well } \\
\text { as take decisions on behalf of the individual CPS as well as ecosystems } \\
\text { of CPS }\end{array}$ \\
\hline $\begin{array}{l}\text { Management of (very) large } \\
\text { scale CPS and CPS SoS }\end{array}$ & $\begin{array}{l}\text { MAS provide mature robust, scalable and flexible solutions, } \\
\text { for managing systems and complex infrastructures }\end{array}$ & Good & $\begin{array}{l}\text { Agent concepts can be used for enhancing management of individual } \\
\text { CPS and CPS-SoS, enabling CPS with the capability to implement } \\
\text { recursivity using the agent technology and following holonic principles }\end{array}$ \\
\hline Real-time control & $\begin{array}{l}\text { Agents in proper settings have been utilized for high-speed } \\
\text { interactions but hardly for closed-loop real-time control }\end{array}$ & Weak & $\begin{array}{l}\text { Agents can be integrated with IEC } 61131-3 \text { and IEC61499 control } \\
\text { applications that guarantee the real-time constraints }\end{array}$ \\
\hline $\begin{array}{l}\text { Security, Trust, Privacy, Re- } \\
\text { silience, Safety }\end{array}$ & $\begin{array}{l}\text { In MAS, several aspects of distributed systems security, code } \\
\text { mobility, operational resiliency, etc., have been investigated }\end{array}$ & Weak & $\begin{array}{l}\text { Agents paradigm can be deployed to carry out security tests, in- } \\
\text { frastructure analysis, intelligently and autonomously maintain the } \\
\text { infrastructure etc. }\end{array}$ \\
\hline
\end{tabular}

in-the-loop. This requires the consideration of adequate methods, methodologies and technologies to develop adaptive and intuitive user interfaces. As an example, maintenance personnel will significantly benefit by using knowledge based tools, complemented with advanced technologies like augmented reality, to support the execution of their tasks. Having this in mind, it is important to note that the selection of technologies to support the integration of Humans is dependent of the application domain, the type of operation to be performed by the human (e.g., availability of hands or level of noise in the environment) and the type of data to be exchanged between the human and the system.

The smooth migration from existing traditional centralized systems to the deployment of new plug-and-produce CPS is mandatory for the industrial adoption of this paradigm, simplifying the use of these principles by system integrators, module and equipment developers and end users. Note that in this process, existing standard automation devices and/or applications may remain in use, which requires the coexistence and integration of these existing systems. Since the use of CPS principles corresponds to an entirely new way of thinking concerning the design of these systems, it is fundamental to create a plethora of assisted procedures that guide system integrators in deploying these systems which can be rapidly changed over. This transformation cannot be performed in one single step but instead requires the implementation of a sequence of steps. For this purpose, the establishment of migration strategies is mandatory for the industrial adoption, with agents playing a fundamental role through the modularization and decentralization that they provide and the encapsulation of their functionalities as services. In this point, the development of standard interfaces (syntax and semantics) and industrial middleware, based on industrial M2M communication protocols, e.g., OPC-UA or DPWS, are important to support the interconnection of heterogeneous systems and devices, contributing for a smooth migration to the new CPS.

The industrial adoption of agent technology requires the capability to implement scalable, resilience and fault-tolerant solutions, allowing the management of large scale CPS. Agents provide the capability to develop flexible and robust solutions (e.g., due to the nonexistence of a central node), but the industrial applications of agents reported in the literature still misses the complete achievement of scalability, which is crucial in industrial environments that requires the simultaneously execution of several hundreds or thousands of agents. For this purpose, the capability to develop industrial agentbased solutions based on the recursive property and following the holonic principles may be useful to achieve scalability. Another important technical issue is related to the connectivity among network components and with legacy systems, being necessary to use infrastructures and protocols that ensure security, safety, fastness and trust.

A key aspect is the integration of complementary technologies to enhance MAS potentialities and overcome its existing limitations. In fact, agent technology can contribute to the development of modular, interoperable and collaborative 
CPS, by encapsulating their functionalities as services, taking advantage of the use of service-orientation principles. For this purpose, the integration of MAS and SOA technologies is a crucial challenge, as well as the establishment of standard interfaces for connecting CPS components, mainly to interface transparently physical automation devices, software systems and legacy systems, contributing to support interoperability. Additionally, the use of proper ontologies will simplify the development of knowledge-driven decision-making systems, especially in case of heterogeneous systems.

Recently we are noticed a tendency towards the integration of MAS with SOA, particularly in manufacturing and electric grids domains, but significant efforts in integrating also other technologies, such as cloud computing, big data techniques, augmented reality, RFID and M2M should be addressed in order to develop more efficient and robust CPS. In particular, embedding data mining algorithms and embodying advanced intelligence and learning algorithms, will contribute, respectively, to achieve big data advanced analytics (collecting, organizing, and analyzing the vast and diverse sensory data) and enhance artificial intelligence in CPS. The use of cloud platforms allows to store big amounts of data and run heavy computational algorithms to process those data. Another similar issue is the integration of agents and IEC 61131-3 and IEC 61499 to ensure the achievement of real-time control of CPS systems.

Methodologies and tools covering the agent's life-cycle management are being pointed out along the time by several surveys and roadmaps as a crucial challenge for the industrial adoption of agent technology. At the moment, the challenge continues valid and there is a demand for methodologies and tools supporting the agents' life-cycle management, especially addressing the industrial requirements. As example, JADE agent-based development framework is widely used to develop MAS-based systems, particularity because it is FIPA compliant, but more robust and efficient tools are need to face the industrial requirements. Namely, the framework should provide [94] security and privacy, real-time interaction protocols for large-scale systems to ensure scalability and latency, light ACL protocols to support scalability in industrial large-scale systems, and truly distributed yellow pages service and discovery mechanisms to improve the system robustness.

\section{CONCLUSION}

CPS is an emerging paradigm addressing the requirements of future industrial systems. CPS advocates the integration of key technologies to face demanding challenges, in terms of flexibility, robustness, adaptation and reconfigurability. MAS will play an important role in this perspective by providing a new and alternative approach design of intelligent and adaptive systems based on the decentralization of control functions.

The paper promotes a discussion of the industrial adoption of MAS in the CPS perspective, particularly focusing the smart production, smart electric grids and smart logistics domains, being noticed a clear increase of the number of industrial applications in the last years. In general, the TRL levels of the deployed industrial applications are still far from the desired, especially in smart production and smart electrical grids.
The paper also discusses the key challenges related to the contribution of agent technology to face the CPS demands in the context of future industrial automation systems. In particular, issues like the modularity, autonomic and self-* features, smooth migration, Human in the loop and simulation can benefit of using agent technology. The standardization issue was also identified as a key aspect in deploying industrial agent-based applications, being necessary to develop solutions compliant with existing industrial standards, but also promoting the establishment of new standards in the field that addresses the industrial requirements.

The complete achievement of CPS will require the integration of MAS with complementary technologies. In particular, MAS can be combined with SOA to reach the system interoperability, with big data techniques and infrastructures for large scale data analytics, with cloud computing for storage and processing of big amounts of data and augmented reality for the human integration.

\section{REFERENCES}

[1] A. W. Colombo and S. Karnouskos, "Towards the factory of the future: A service-oriented cross-layer infrastructure," in ICT Shaping the World: A Scientific View. European Telecommunications Standards Institute (ETSI), John Wiley and Sons, 2009, pp. 65-81.

[2] ACATECH, "Cyber-Physical Systems: Driving force for innovation in mobility, health, energy and production," ACATECH - German National Academy of Science and Engineering, Tech. Rep., Dec. 2011.

[3] H. Kagermann, W. Wahlster, and J. Helbig, "Securing the future of German manufacturing industry: Recommendations for implementing the strategic initiative INDUSTRIE 4.0," German National Academy of Science and Engineering (ACATECH), Tech. Rep., 2013. [Online]. Available: http://www.acatech.de/fileadmin/user_upload/Baumstruktur_ nach_Website/Acatech/root/de/Material_fuer_Sonderseiten/Industrie_4. 0/Final_report_Industrie_4.0_accessible.pdf

[4] S.-W. Lin, B. Miller, J. Durand, R. Joshi, P. Didier, A. Chigani, R. Torenbeek, D. Duggal, R. Martin, G. Bleakley, A. King, J. Molina, S. Schrecker, R. Lembree, H. Soroush, J. Garbis, M. Crawford, E. Harper, K. Raman, and B. Witten, "Industrial Internet Reference Architecture," Industrial Internet Consortium (IIC), Tech. Rep., Jun. 2015. [Online]. Available: http://www.iiconsortium.org/IIRA-1-7ajs.pdf

[5] L. Monostori, "Cyber-physical production systems: Roots, expectations and R\&D challenges," Procedia CIRP, vol. 17, pp. 9-13, 2014.

[6] S. Karnouskos, A. W. Colombo, T. Bangemann, K. Manninen, R. Camp, M. Tilly, P. Stluka, F. Jammes, J. Delsing, and J. Eliasson, "A SOAbased architecture for empowering future collaborative cloud-based industrial automation," in 38th Annual Conference of the IEEE Industrial Electronics Society (IECON'12), Oct. 2012, pp. 5766-5772.

[7] Gartner's 2015 Hype cycle for emerging technologies identifies the computing innovations that organizations should monitor. [Online]. Available: http://www.gartner.com/newsroom/id/3114217

[8] P. Leitão and S. Karnouskos, Eds., Industrial Agents: Emerging Applications of Software Agents in Industry. Elsevier, Mar. 2015.

[9] P. Leitão, "Agent-based distributed manufacturing control: A stateof-the-art survey," Engineering Applications of Artificial Intelligence, vol. 22, no. 7, pp. 979-991, Oct. 2009.

[10] PCAST, "Designing a digital future: Federally funded research and development in networking and information technology," USA Executive Office of the President President's Council of Advisors on Science and Technology (PCAST), Tech. Rep., Dec. 2010. [Online]. Available: http://www.whitehouse.gov/sites/default/files/microsites/ostp/ pcast-nitrd-report-2010.pdf

[11] A. W. Colombo, T. Bangemann, S. Karnouskos, J. Delsing, P. Stluka, R. Harrison, F. Jammes, and J. L. Martínez Lastra, Eds., Industrial Cloud-based Cyber-Physical Systems: The IMC-AESOP Approach. Springer, 2014

[12] P. Leitão, V. Mař́k, and P. Vrba, "Past, present, and future of industrial agent applications," IEEE Transactions on Industrial Informatics, vol. 9 , no. 4, pp. 2360-2372, Nov. 2013. 
[13] L. Monostori, J. Váncza, and S. Kumara, "Agent-based systems for manufacturing," CIRP Annals - Manufacturing Technology, vol. 55, no. 2, pp. 697-720, Jan. 2006.

[14] V. Mařík and D. McFarlane, "Industrial adoption of agent-based technologies," IEEE Intell. Syst., vol. 20, no. 1, pp. 27-35, Jan. 2005.

[15] V. Mař́k and J. Lažanský, "Industrial applications of agent technologies," Control Engineering Practice, vol. 15, no. 11, pp. 1364-1380, Nov. 2007.

[16] T. Strasser, F. Andren, J. Kathan, C. Cecati, C. Buccella, P. Siano, P. Leitão, G. Zhabelova, V. Vyatkin, P. Vrba, and V. Mařík, "A review of architectures and concepts for intelligence in future electric energy systems," IEEE Trans. Ind. Electron., vol. 62, no. 4, pp. 2424-2438, Apr. 2015

[17] P. Vrba, V. Mařík, P. Siano, P. Leitão, G. Zhabelova, V. Vyatkin, and T. Strasser, "A review of agent and service-oriented concepts applied to intelligent energy systems," IEEE Transactions on Industrial Informatics, vol. 10, no. 3, pp. 1890-1903, Aug. 2014.

[18] S. Karnouskos, A. Weidlich, J. Ringelstein, A. Dimeas, K. Kok, C. Warmer, P. Selzam, S. Drenkard, N. Hatziargyriou, and V. Lioliou, "Monitoring and control for energy efficiency in the smart house," in Lecture Notes of the Institute for Computer Science. Springer, 2011 vol. 54, pp. 197-207.

[19] M. Furmankiewicz, A. Sołtysik-Piorunkiewicz, and P. Ziuziański, "Artificial intelligence and multi-agent software for e-health knowledge management systems," Business Informatics, vol. 2, no. 32, pp. 51-62, 2014.

[20] F. Bergenti and A. Poggi, "Multi-agent systems for e-health: Recent projects and initiatives," in 10th International Workshop on Objects and Agents, 2009.

[21] V. Mařík, P. Vrba, K. Hall, and F. Maturana, "Rockwell automation agents for manufacturing," in Fourth International Joint conference on Autonomous Agents and Multiagent Systems (AAMAS'05). ACM, 2005, pp. 107-113.

[22] H. Wada, Y. Sakuraba, and M. Negishi, "Machinery Control System using Autonomous Agents," in Autonomous Agents 2000 Workshop: Agents in Industry, $4^{\text {th }}$ International Conference on Autonomous Agents, Barcelona, Spain, 2000

[23] S. Brückner, J. Wyns, P. Peeters, and M. Kollingbaum, "Designing agents for the manufacturing control," in Artificial Intelligence and Manufacturing Workshop, 1998, pp. 40-46.

[24] S. Bussmann and K. Schild, "An agent-based approach to the control of flexible production systems," in $8^{\text {th }}$ International Conference on Emerging Technologies and Factory Automation (ETFA'01), 2001, pp. 481-488.

[25] M. Pechoucek, A. Riha, J. Vokrinek, V. Marik, and V. Prazma, "ExPlanTech: Applying multi-agent systems in production planning," International Journal of Production Research, vol. 40, no. 15, pp. 36813692, Jan. 2002

[26] M. Fletcher, D. McFarlane, A. Thorne, D. Jarvis, and A. Lucas, "Evaluating a holonic packing cell," in Holonic and Multi-Agent Systems for Manufacturing. Springer, 2003, vol. 2744, pp. 246-257.

[27] D. Djurdjanovic, J. Lee, and J. Ni, "Watchdog agent-an infotronicsbased prognostics approach for product performance degradation assessment and prediction," Advanced Engineering Informatics, vol. 17, no. 3-4, pp. 109-125, Jul. 2003.

[28] L. Mönch, M. Stehli, and J. Zimmermann, "FABMAS: An agentbased system for production control of semiconductor manufacturing processes," in Holonic and Multi-Agent Systems for Manufacturing. Springer, 2003, vol. 2744, pp. 258-267.

[29] A. Lüder, J. Peschke, T. Sauter, S. Deter, and D. Diep, "Distributed intelligence for plant automation based on multi-agent systems: the pabadis approach," Production Planning \& Control, vol. 15, no. 2, pp. 201-212, 2004.

[30] J. L. M. Lastra, E. L. Torres, and A. W. Colombo, "A 3D visualization and simulation framework for intelligent physical agents," in Holonic and Multi-Agent Systems for Manufacturing. Springer, 2005, vol. 3593, pp. 23-38.

[31] S. Jacobi, C. Madrigal-Mora, E. León-Soto, and K. Fischer, "Agentsteel: an agent-based online system for the planning and observation of steel production," in Fourth International Joint conference on Autonomous Agents and Multiagent Systems (AAMAS'05). ACM, 2005, pp. 114119.

[32] S. Karnouskos and M. M. J. Tariq, "An agent-based simulation of SOAready devices," in Proceedings of the $10^{\text {th }}$ International Conference on Computer Modeling and Simulation (UKSIM'08), 2008, pp. 330-335.

[33] _ - "Using multi-agent systems to simulate dynamic infrastructures populated with large numbers of web service enabled devices," in Inter- national Symposium on Autonomous Decentralized Systems (ISADS'09), Mar. 2009, pp. 1-7.

[34] A. W. Colombo, S. Karnouskos, J. M. Mendes, and P. Leitão, "Industrial Agents in the Era of Service Oriented Architectures and Cloud based Industrial Infrastructures," in Industrial Agents: Emerging Applications of Software Agents in Industry. Elsevier, Mar. 2015, pp. 67-87.

[35] G. Cândido and J. Barata, "A multiagent control system for shop floor assembly," in Holonic and Multi-Agent Systems for Manufacturing. Springer, 2007, vol. 4659, pp. 293-302.

[36] P. Blanc, I. Demongodin, and P. Castagna, "A holonic approach for manufacturing execution system design: An industrial application," Engineering Applications of Artificial Intelligence, vol. 21, no. 3, pp. 315-330, Apr. 2008.

[37] P. Leitão and F. Restivo, "Implementation of a holonic control system in a flexible manufacturing system," IEEE Transactions on Systems, Man, and Cybernetics, Part C (Applications and Reviews), vol. 38, no. 5, pp. 699-709, Sep. 2008.

[38] M. Andreev, "A multi-agent platform design for adaptive networks of intelligent production schedulers," in 10th IFAC Workshop on Intelligent Manufacturing Systems (IMS'10), Jul. 2010.

[39] S. Karnouskos, V. Havlena, E. Jerhotova, P. Kodet, M. Sikora, P. Stluka P. Trnka, and M. Tilly, "Plant energy management," in Industrial Cloudbased Cyber-Physical Systems: The IMC-AESOP Approach. Springer, May 2014, pp. 1-17.

[40] P. Skobelev, "Multi-agent system smart factory for real-time workshop management in aircraft jet engines production," in 11th IFAC Workshop on Intelligent Manufacturing Systems (IMS'13). Elsevier BV, 2013.

[41] P. Leitão, N. Rodrigues, C. Turrin, and A. Pagani, "Multiagent system integrating process and quality control in a factory producing laundry washing machines," IEEE Transactions on Industrial Informatics, vol. 11, no. 4, pp. 879-886, Aug. 2015.

[42] L. Ribeiro, J. Barata, M. Onori, and J. Hoos, "Industrial Agents for the Fast Deployment of Evolvable Assembly Systems Industrial Agents," in Industrial Agents: Emerging Applications of Software Agents in Industry. Elsevier, Mar. 2015, pp. 301-322.

[43] C. Marín, L. Mönch, P. Leitão, P. Vrba, D. Kazanskaia, V. Chepegin, L. Liu, and N. Mehandjiev, "A conceptual architecture based on intelligent services for manufacturing support systems," in IEEE International Conference on Systems, Man, and Cybernetics (SMC'13), Oct. 2013, pp. 4749-4754.

[44] J. Barbosa, P. Leitão, E. Adam, and D. Trentesaux, "Dynamic selforganization in holonic multi-agent manufacturing systems: The ADACOR evolution," Computers in Industry, vol. 66, pp. 99-111, Jan. 2015.

[45] A. Rocha, G. di Orio, J. Barata, N. Antzoulatos, E. Castro, D. Scrimieri, S. Ratchev, and L. Ribeiro, "An agent based framework to support plug and produce," in $12^{\text {th }}$ IEEE International Conference on in Industrial Informatics (IECON'14), Jul. 2014, pp. 504-510.

[46] A. Lüder, A. Klostermeyer, J. Peschke, A. Bratoukhine, and T. Sauter, "Distributed automation: PABADIS versus HMS," IEEE Transactions on Industrial Informatics, vol. 1, no. 1, pp. 31-38, Feb 2005.

[47] A. Colombo, S. Karnouskos, and J. Mendes, "Factory of the future: A service-oriented system of modular, dynamic reconfigurable and collaborative systems," in Springer Series in Advanced Manufacturing. Springer, 2010, pp. 459-481.

[48] K. Kok, "The PowerMatcher: Smart Coordination for the Smart Electricity Grid," Ph.D. dissertation, Vrije Universiteit, 2013. [Online]. Available: http://hdl.handle.net/1871/43567

[49] D. A. Cohen, "Gridagents: Intelligent agent applications for integration of distributed energy resources within distribution systems," in IEEE Power and Energy Society General Meeting - Conversion and Delivery of Electrical Energy in the 21 $1^{\text {st }}$ Century, Jul. 2008, pp. 1-5.

[50] K. Kok, Z. Derzsi, J. Gordijn, M. Hommelberg, C. Warmer, R. Kamphuis, and H. Akkermans, "Agent-based electricity balancing with distributed energy resources, a multiperspective case study," in $41^{s t} \mathrm{An}$ nual Hawaii International Conference on System Sciences (HICSS'08). IEEE, Jan. 2008.

[51] M. Pipattanasomporn, H. Feroze, and S. Rahman, "Multi-agent systems in a distributed smart grid: Design and implementation," in IEEE Power Systems Conference and Exposition (PSCE'09), Mar. 2009, pp. 1-8.

[52] A. Dimeas, S. Drenkard, N. Hatziargyriou, S. Karnouskos, K. Kok, J. Ringelstein, and A. Weidlich, "Smart Houses in the Smart Grid: Developing an interactive network," IEEE Electrification Magazine, vol. 2, no. 1, pp. 81-93, Mar. 2014.

[53] S. Karnouskos and T. N. de Holanda, "Simulation of a smart grid city with software agents," in Third UKSim European Symposium on Computer Modeling and Simulation. IEEE, 2009, pp. 424-429.

[54] M. Maenhoudt and G. Deconinck, "Agent-based modelling as a tool for 
testing electric power market designs," in $7^{\text {th }}$ International Conference on the European Energy Market. IEEE, Jun. 2010.

[55] A. Dimeas and N. Hatziargyriou, "Control agents for real microgrids," in $15^{\text {th }}$ International Conference on Intelligent System Applications to Power Systems, Nov. 2009, pp. 1-5.

[56] G. Peppink, R. Kamphuis, K. Kok, A. Dimeas, E. Karfopoulos, N. Hatziargyriou, N. Hadjsaid, R. Caire, R. Gustavsson, J. M. Salas, H. Niesing, J. van der Velde, L. Tena, F. Bliek, M. Eijgelaar, L. Hamilton, and H. Akkermans, "INTEGRAL: ICT-platform based distributed control in electricity grids with a large share of distributed energy resources and renewable energy sources," in Lecture Notes of the Institute for Computer Sciences, Social Informatics and Telecommunications Engineering. Springer, 2011, pp. 215-224.

[57] M. Merdan, W. Lepuschitz, T. Strasser, and F. Andren, "Multi-agent system for self-optimizing power distribution grids," in $5^{\text {th }}$ International Conference on Automation, Robotics and Applications. IEEE, Dec. 2011.

[58] M. Perdikeas, T. Zahariadis, and P. Plaza, "The BeyWatch conceptual model for demand-side management," in Energy-Efficient Computing and Networking. Springer, 2011, vol. 54, pp. 177-186.

[59] D. Gantenbein, C. Binding, B. Jansen, A. Mishra, and O. Sundström, "EcoGrid EU: An efficient ICT approach for a sustainable power system," in Sustainable Internet and ICT for Sustainability (SustainIT), 2012, pp. 1-6.

[60] R. F. Boehm, "An approach to decreasing the peak electrical demand in residences," Energy Procedia, vol. 14, pp. 337-342, 2012.

[61] GRID4EU, "D1.2 report of development for flexible MV-network operation," European Union FP7 Project GRID4EU, Tech. Rep., 2013. [Online]. Available: http://grid4eu.blob.core.windows.net/mediaprod/19198/grid4eu_demo1_deliverable_dd12_final.pdf

[62] P. Goncalves da Silva, D. Ilic, and S. Karnouskos, "The impact of smart grid prosumer grouping on forecasting accuracy and its benefits for local electricity market trading," IEEE Trans. Smart Grid, vol. 5, no. 1, pp. 402-410, Jan. 2014.

[63] S. Karnouskos, "Agent-based mediated control in smart grids," in $2^{\text {nd }}$ IEEE PES International Conference and Exhibition on Innovative Smart Grid Technologies, Dec. 2011.

[64] G. Fortino and A. Guerrieri, "Decentralized management of building indoors through embedded software agents," Comput. Sci. Inf. Syst., vol. 9, no. 3, pp. 1331-1359, 2012.

[65] R. Bottura and A. Borghetti, "Simulation of the Volt/Var control in distribution feeders by means of a networked multiagent system," IEEE Transactions on Industrial Informatics, vol. 10, no. 4, pp. 2340-2353, Nov. 2014.

[66] T. K. Wijaya, K. Larson, and K. Aberer, "Matching demand with supply in the smart grid using agent-based multiunit auction," in Fifth International Conference on Communication Systems and Networks (COMSNETS'13). IEEE, Jan. 2013.

[67] Z. Jiang, "Agent-based control framework for distributed energy resources microgrids," in IEEE/WIC/ACM International Conference on Intelligent Agent Technology, 2006, pp. 646-652.

[68] S. Rivera, A. Farid, and K. Youcef-Toumi, "A multi-agent system transient stability platform for resilient self-healing operation of multiple microgrids," in IEEE PES Innovative Smart Grid Technologies Conference (ISGT'14), Feb. 2014

[69] S. B. Ghosn, P. Ranganathan, S. Salem, J. Tang, D. Loegering, and K. E. Nygard, "Agent-oriented designs for a self healing smart grid," in First IEEE International Conference on Smart Grid Communications, Oct. 2010, pp. 461-466.

[70] K. Moslehi, A. Kumar, D. Shurtleff, M. Laufenberg, A. Bose, and P. Hirsch, "Framework for a self-healing power grid," in IEEE Power Engineering Society General Meeting, 2005.

[71] E. Bonabeau and C. Meyer, "Swarm intelligence: A whole new way to think about business," Harvard Business Review, vol. 79, no. 5, pp. 107-114, May 2001.

[72] K. Dorer and M. Calisti, "An adaptive solution to dynamic transport optimization," in Fourth International Joint Conference on Autonomous Agents and Multiagent Systems (AAMAS'05). ACM, 2005, pp. 45-51.

[73] P. Skobelev, A. Glaschenko, I. Grachev, and S. Inozemtsev, "MAGENTA Technology Case Studies of Magenta I-scheduler for Road Transportation," in $6^{\text {th }}$ International Joint Conference on Autonomous Agents and Multiagent Systems (AAMAS'07). ACM, 2007, pp. 273:1-273:8.

[74] C. N. Harper and L. Davis, "Evolutionary computation at American air liquide," in Evolutionary Computation in Practice. Springer, 2008, vol. 88 , pp. 313-317

[75] U. Inden, G. Rzevski, P. Skobelev, I. Syusin, and A. Tsarev, "Multiagent adaptive planning platform for complex airport services," in $10^{\text {th }}$
Intern. Conf. on Problems of Control in Complex Systems, 2008, pp. 399-413.

[76] A. Glaschenko, A. Ivaschenko, G. Rzevski, and P. Skobelev, "Multiagent real time scheduling system for taxi companies," in $8^{\text {th }}$ Int. Conf. on Autonomous Agents and Multiagent Systems (AAMAS'09), May 2009, pp. 29-36.

[77] S. Andreev, G. Rzevski, P. Shviekin, P. Skobelev, and I. Yankov, "A multi-agent scheduler for rent-a-car companies," in Holonic and MultiAgent Systems for Manufacturing. Springer, 2009, vol. 5696, pp. 305314.

[78] P. G. Ansola, J. de las Morenas, A. García, and J. Otamendi, "Distributed decision support system for airport ground handling management using WSN and MAS," Engineering Applications of Artificial Intelligence, vol. 25, no. 3, pp. 544-553, Apr. 2012.

[79] O. Granichin, P. Skobelev, A. Lada, I. Mayorov, and A. Tsarev, "Comparing adaptive and non-adaptive models of cargo transportation in multi-agent system for real time truck scheduling," in $4^{\text {th }}$ International Joint Conference on Computational Intelligence. Scitepress, 2012, pp. 282-285.

[80] B. Madsen, G. Rzevski, P. Skobelev, and A. Tsarev, "A strategy for managing complexity of the global market and prototype real-time scheduler for LEGO supply chain," International Journal of Software Innovation, vol. 1, no. 2, pp. 28-39, 2013.

[81] A. Castro, A. P. Rocha, and E. Oliveira, A New Approach for Disruption Management in Airline Operations Control. Springer Berlin Heidelberg, 2014.

[82] A. Belousov, P. Skobelev, and M. Stepanov, "Network-centric approach to real-time train scheduling in large-scale railway systems," in Advances in Swarm and Computational Intelligence. Springer, 2015, vol. 9141 , pp. 290-299.

[83] A. Farid and L. Ribeiro, "An axiomatic design of a multiagent reconfigurable mechatronic system architecture," IEEE Transactions on Industrial Informatics, vol. 11, no. 5, pp. 1142-1155, Oct. 2015.

[84] E. Crawley, O. de Weck, S. Eppinger, C. Magee, J. Moses, W. Seering, J. Schindall, D. Wallace, and D. Whitney, "The influence of architecture in engineering systems," Engineering Systems Monograph, vol. 2006, 2004. [Online]. Available: http://esd.mit.edu/symposium/ pdfs/monograph/architecture-b.pdf

[85] L. Ribeiro, "The Design, Deployment and Assessment of Industrial Agent Systems," in Industrial Agents: Emerging Applications of Software Agents in Industry. Elsevier, Mar. 2015, pp. 45-63.

[86] L. Ribeiro, J. Barata, and P. Mendes, "MAS and SOA: Complementary Automation Paradigms," in IFIP Innovation in Manufacturing Networks, A. Azevedo, Ed. Springer, 2008, vol. 266, pp. 259-268.

[87] J. Mendes, P. Leitão, F. Restivo, and A. W. Colombo, "Service-oriented agents for collaborative industrial automation and production systems," in Holonic and Multi-Agent Systems for Manufacturing, Lecture Notes in Computer Science, V. Mařík, T. Strasser, and A. Zoitl, Eds. Springer Berlin Heidelberg, 2009, vol. 5696, pp. 13-24.

[88] A. Otto and K. Hellmann, "IEC 61131: A general overview and emerging trends," IEEE Industrial Electronics Magazine, vol. 3, no. 4, pp. 27-31, Dec. 2009.

[89] V. Vyatkin, "IEC 61499 as enabler of distributed and intelligent automation: State-of-the-art review," IEEE Transactions on Industrial Informatics, vol. 7, no. 4, pp. 768-781, Nov. 2011.

[90] W. Mahnke, S.-H. Leitner, and M. Damm, OPC Unified Architecture. Springer, 2009

[91] T. Strasser and A. Zoitl, "Distributed real-time automation and control - reactive control layer for industrial agents," in Industrial Agents: Emerging Applications of Software Agents in Industry. Elsevier, Mar. 2015, pp. 89-107.

[92] P. Leitão, A. W. Colombo, and S. Karnouskos, "Industrial automation based on cyber-physical systems technologies: Prototype implementations and challenges," Computers in Industry, in Press.

[93] P. Leitão and S. Karnouskos, "A Survey on Factors that Impact Industrial Agent Acceptance," in Industrial Agents: Emerging Applications of Software Agents in Industry. Elsevier, Mar. 2015, pp. 401-429.

[94] P. Leitão, J. Barbosa, M.-E. C. Papadopoulou, and I. S. Venieris, "Standardization in cyber-physical systems: The ARUM case," in IEEE International Conference on Industrial Technology (ICIT'15), Mar. 2015, pp. 2988-2993. 